\title{
RADIATION-INDUCED EFFECTS IN SILICON
}

\author{
G.P. Gaidar, M.B. Pinkovska, M.I. Starchyk \\ Institute for Nuclear Research of the National Academy of Sciences of Ukraine, Kyiv, Ukraine \\ E-mail: gaydar@kinr.kiev.ua
}

Results of complex studies of the structural properties of silicon irradiated with light ions of megaelectronvolt energies by fluences greater than $10^{16} \mathrm{~cm}^{-2}$ are presented. It was found that during irradiation under conditions of large energy release in thin layer of crystal, the favorable conditions can be created for the controlled introduction of structural defects and the appearance of the effects of ordering and long-range. The possibility of layer-by-layer modification of the properties of silicon at depths up to $780 \mu \mathrm{m}$ under irradiation with ions was established that can be used to provide the actual needs of micro- and nanoelectronics.

PACS 61.82.Fk

\section{INTRODUCTION}

It is difficult to overestimate the limits of the use of ion beams in modern micro- and nanoelectronics [1,2] An ordered and controlled introduction into the crystal of the impurity or intrinsic defects and their complexes by means of the ion irradiation makes it possible to create the hidden regions with properties different from those of the matrix. The size, shape, and location of such modified regions depend on the irradiation conditions: the energy and mass of the ions, the fluence and intensity, the irradiation temperature and the properties of the crystals.

The implantation of gases $(\mathrm{H}, \mathrm{Ne}, \mathrm{Ar}, \mathrm{He})$ is interesting due to the possibility of an orderly introduction of nanovoids into the crystal [3-5]. Such voids have clean internal surfaces that can getter any undesirable impurities from the volume of the crystal and serve as centers of relaxation of stresses in the surrounding lattice [6]. The conditions for obtaining the ordered structures in the irradiated crystals are large ion fluences or a significant current density of ion beams. Under such conditions the segregation and anomalous transfer (diffusion) of impurities and defects might occur.

Currently, the doping of silicon by ions of kiloelectronvolt energies is most fully studied, since for many years it has been the basis of various opto-, nano-, and sensor devices, integrated in silicon substrates. With the creation of powerful accelerators, the application of heavy ions of several hundred megaelectronvolt energies has become promising [7]. Incorporated into the crystal, ions cause local excitation and ionization of the atoms without any direct their displacement, and in the material the hidden tracks along the ion path are formed. As a result, after special treatment silicon becomes a nanostructured material.

In recent decades, the new phenomena (such as an increase in microhardness, phase transformations, the formation of a periodic structure in the distribution of defects, the change in the lattice parameter, etc.) have been observed, which appeared behind the ion path during the ion implantation into crystal. For these effects, the special name was proposed - long-range effects. In the numerous experimental studies, the radiative influences of the accelerated heavy ions were observed by various methods at the depths, which in some cases exceeded the calculated (projection) paths $\left(R_{p}\right)$ of ions by orders of magnitude [8]. As applied to accelerated atomic particles, the long-range effect means the possibility of the propagation of a defective structure to anomalously large distances in the target material $[9,10]$. Regarding the action of light ions that are not used in the technology of ion doping, the features of the long-range effect are not well understood. The mechanism of its occurrence is still unexplained.

The long-range effects are one of the most important problems of the radiation damage of materials. On the one hand, the distribution of radiation defects and implanted ions in depth is of primary technical interest, since in many cases this information is important for the radiation modification of materials. On the other hand, the study of these effects are of the fundamental importance for understanding the nature of the interaction of irradiation with a substance, because in the existing models this nature is describe quite simplified.

To explain the long-range effects, the various assumptions are made regarding: a) the important role of radiation-stimulated diffusion caused by mechanical stresses that are created by irradiation; b) the role of cascades formed during irradiation; c) the appearance of solitons; d) the role of self-organization processes etc. All these processes can take place, however, despite of the numerous studies, most of the effects cannot be explained currently. Existing theories, which are based on the idea of a pair interaction of fast particles with atomic substances, give the distribution of radiation defects only in the range of ion path and braking.

Theoretical models of interaction of radiation with crystals, which describe well enough the behavior of individual radiation defects or their complexes in solids, are unsuitable in the case of prolonged irradiation and the intensive ion beams, when a large number of defects accumulate in a limited volume and their collective interaction must be taken into account. It turned out that the range of light ions with energies of tens megaelectronvolt, which became the object of our research, remains the least studied in this regard.

The aim of the work was to establish the features of the formation of the microstructure of near-surface layers of silicon irradiated with high-energy light ions (hydrogen, deuterium and helium); to compare the formed defects in the ion path, in the braking region and behind the braking area of the ions; to analyze and generalize of the obtained results of the carried out complex studies. 


\section{EXPERIMENT}

The effect of high-energy (tens of megaelectronvolt) light ions on the structure of Si was investigated in order to analyze the possibilities of modifying locally the crystal properties. First of all, except hydrogen, there were the other ions (deuterium, helium) with energies from the less studied range. Usage of particles which energies and masses differ was convenient for the comparison of structural changes, induced by different ions. The second, all ions under research were gasses. And finally, the obtained experimental data concerning the radiation effects of light ions on the material in the areas of their path, braking, and also at the depths that significantly exceed the area of their penetration can be useful when building the adequate theory of interaction of the high-energy ions with a crystal. Therefore it is necessary to conduct researches in this direction to improve the understanding of these processes and to control further of them.

Single crystals of $n-\mathrm{Si}(\rho=3 \ldots 4 \mathrm{k} \Omega \cdot \mathrm{cm})$ grown by Czochralski method, dislocation-free and with a dislocation density of $N_{D} \approx 10^{3} \mathrm{~cm}^{-2}$ are investigated. Irradiation of silicon crystals by hydrogen ions (protons) with an energy of 6.8 , by 13.6 deuterium ions (deuterons) and $27.2 \mathrm{MeV}$ helium ions ( $\alpha$-particles) by fluences $\Phi \geq 10^{16} \ldots 10^{17} \mathrm{~cm}^{-2}$ with varying the ion beam current density from 0.25 to $3 \mu \mathrm{A} / \mathrm{cm}^{2}$ was carried out at cyclotrons U-120 of the Institute for Nuclear Research of the NAS of Ukraine. The dislocation-free crystals were irradiated by the hydrogen and helium ions, and crystals containing dislocations were irradiated by deuterium ions. Silicon samples of $1 . .2 \mathrm{~mm}$ thickness were glued to the substrate of the special holder, which was cooled with running water during irradiation. In this case, the sample was cooled also along the edges of the surface; meanwhile the temperature of sample did not exceed $100^{\circ} \mathrm{C}$. Irradiated samples were cut along the direction of irradiation (allowing studying the properties of silicon in the ion path region, braking and behind the braking area). To study the topographic image of the defective silicon microstructure, the mechanical (grinding) and chemical (polishing) surface treatments were carried out; in some cases samples were thinned by gradual etching from the side of irradiated surface, then the surfaces of the samples were examined on a metal-microscope, atomic-force microscope (AFM) and scanning electron microscope (SEM). The crosssections of the irradiated samples were also studied by the X-ray topography method (Lang method).

\section{RESULTS AND DISCUSSION}

It is known that the introduced ions moving through a crystal gradually lose their energy during excitation and ionization before deceleration, where, during elastic collisions with atoms, they displace atoms and cause radiation defects. That is why during study the irradiated material is divided into several regions: ion path region, braking area and behind the braking area. The size of regions is determined by the type of ions, their mass, energy, and temperature during irradiation. In the silicon the projection (calculated) path length of the hydrogen and helium ions of the utilized energies are nearly the same, $R_{p} \approx 360 \mu \mathrm{m}$, and is larger in the case of $13.6 \mathrm{MeV}$ deuterium ions, about $780 \mu \mathrm{m}$.

\subsection{MICRODEFECT STRUCTURE OF SILICON IRRADIATED BY HYDROGEN IONS}

The influence of high-energy hydrogen ions on solids differs essentially from that of other types of radiation. Though point defects are the dominating type of defects generated by electrons and gamma-quanta, and complicated defects of the disordered-region type are typical of neutrons, a variety of defect types are formed at the hydrogen ion slowing-down in elastic and inelastic collisions with substance atoms owing to a wide range of the recoil energy. A characteristic feature of the high-energy hydrogen ion irradiation is the fact that, besides small and relatively large damaged regions (complex formations like disordered regions) in a solid, large smeared regions with a low density of defects in them are formed as well [11]. In Refs. [12, 13], the formation of the defect clusters (the disordered regions) of the divacancy type and the point vacancy-impurity defects in the hydrogen ion path region of crystal was detected. The efficiency of the introduction of the latter with such irradiation is two-three orders of magnitude higher than with neutron.

In silicon irradiated by hydrogen ions with the energy of $6.8 \mathrm{MeV}$ by fluence of $10^{17} \mathrm{~cm}^{-2}$, on the scanning electron micrograph of the sample, cut along the direction of irradiation, only one stress line appeared at a depth of $\sim R_{p}$. However, observations on a metalmicroscope revealed on the same sample two stress lines associated with defects at distances of 358 and $645 \mu \mathrm{m}\left(\sim 2 R_{p}\right)$ from the surface from the irradiation side [14]. The presence of the second stress line at the distance of double ion path is a manifestation of the long-range effect. With respect to accelerated atomic particles, this effect means the possibility of the propagation of a defective structure over abnormally large distances in the target material.

The width of the first etched line (braking line 1 in Fig. 1) was about $50 \ldots 80 \mu \mathrm{m}$, and the depth determined by profilometry was $10 \ldots 50 \mu \mathrm{m}$. The width of the second etched line (the long-range effect) was about 20...30 $\mu \mathrm{m}$.

Picture of selective etching of silicon irradiated by $6.8 \mathrm{MeV}$ hydrogen ions with fluence of $10^{17} \mathrm{~cm}^{-2}$ is given in Fig. 1. The stress line in the braking area was wider in the center of irradiated region (see Fig. 1,b) and narrowed to the periphery, reaching a minimum value at the edge of the irradiated region (see Fig. 1,a), where the temperature at irradiation was lower due to cooling.

In the center of the irradiated region of the sample at the beam current density of hydrogen ions $\leq 0.45 \mu \mathrm{A} / \mathrm{cm}^{2}$ at a distance from the surface equal to double path length of the ions $\left(2 R_{p}\right)$, a second etched line of stress was observed parallel to the braking line (see Fig. 1,b). The dependence of the propagation of defects behind the braking line of hydrogen ions on the value of the ion beam current density, that is, on the intensity of irradiation, is revealed. 

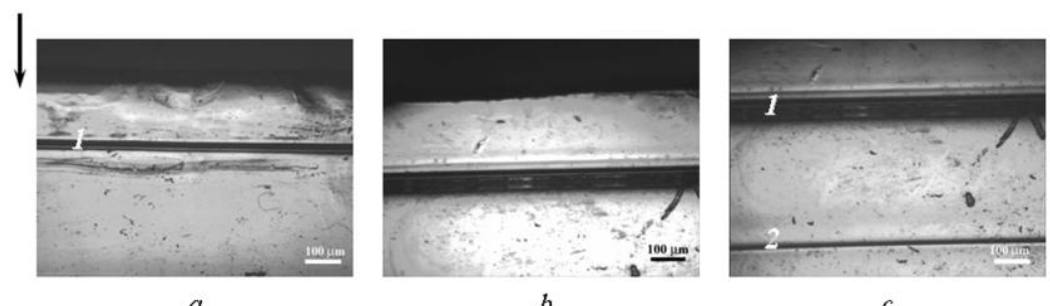

Fig. 1. Micrographs of the etched lines of stresses, which appears at a distance of the ion path length $R_{p}=360 \mu \mathrm{m}$ (line 1) from the surface of $n$-Si irradiated with $6.8 \mathrm{MeV}$ hydrogen ions by fluence $\Phi=10^{17} \mathrm{~cm}^{-2}:$ a - at the edge;

$b$-closer to the center; $c$-in the center of the irradiated region of the sample line 2 appears at a distance of double hydrogen ion path $\left(2 R_{p}\right)$ (the long-range effect at the ion beam current density $\leq 0.45 \mu \mathrm{A} / \mathrm{cm}^{2}$ ).

The arrow indicates the direction of irradiation

When the current density was increased to $1 \mu \mathrm{A} / \mathrm{cm}^{2}$, the stress line 2 in silicon was not observed behind the braking line 1 . At the beam current density of $3 \mu \mathrm{A} / \mathrm{cm}^{2}$ under similar cooling conditions (the sample was cooled only by the running water) the part of silicon (with a thickness that corresponds to the path depth) at the passage of ions was exfoliated from the crystal volume during irradiation. This fact indicated that the temperature of silicon in the braking region reached a value sufficient to release of hydrogen from $\mathrm{Si}-\mathrm{H}$ bonds and to fill them vacancy complexes in the process of irradiation. According to Ref. [12], hydrogen released from $\mathrm{Si}-\mathrm{H}$ bonds at the temperature near of $600{ }^{\circ} \mathrm{C}$, formed bubbles that grew and burst to create the voids (pores), the size and density of which were determined by the energy of protons and the irradiation intensity. At the low beam current density of $0.25 \ldots 0.45 \mu \mathrm{A} / \mathrm{cm}^{2}$, irradiated part of silicon was exfoliated only after the annealing of irradiated silicon at $600{ }^{\circ} \mathrm{C}$, that is, the effect was determined by the temperature of the sample annealing.

The distributions of the structural defects near the braking area of hydrogen ions in silicon were obtained by X-ray topography and selective etching methods after the gradual etching of the surface of irradiated silicon (from the side of irradiation) with the step of $30 \mu \mathrm{m}$. The Si samples were previously irradiated at $T \leq 100{ }^{\circ} \mathrm{C}$ with $10^{17} \mathrm{~cm}^{-2}$ hydrogen ion fluence and annealed at $580^{\circ} \mathrm{C}$ for $0.5 \mathrm{~h}$. Namely under these conditions hydrogen begins to be released from the $\mathrm{Si}-\mathrm{H}$ bonds. The results obtained help us to understand the behavior of hydrogen in $\mathrm{Si}$ when the temperature of sample during irradiation is possible higher.

Fig. 2 show the pictures of X-ray topography (see Fig. 2-I,a-d) and selective etching (see Fig. 2-II,e-h) of the sample taken in the irradiation plane at the depth of $315 \ldots 510 \mu \mathrm{m}$ from the irradiated surface. Taking into account that the projection path length of hydrogen ions with energy of $6.8 \mathrm{MeV}$ is about $360 \mu \mathrm{m}$, the data are obtained for $45 \mu \mathrm{m}$ (a) and $10 \mu \mathrm{m}$ (b) to the braking line, as well as for $35 \mu \mathrm{m}$ (c) and $150 \mu \mathrm{m}$ (d) behind it (see Fig. 2-I). One can see that the irradiated area associated with radiation defects is gradually decrease under deepening in material and completely disappears at the depth of about $510 \mu \mathrm{m}$ from the irradiated surface (nearly $150 \mu \mathrm{m}$ behind the braking line). The layers of growth of the matrix silicon were detected at the depth of about $395 \mu \mathrm{m}$ (see Fig. 2-I,c), that is nearly $35 \mu \mathrm{m}$ behind the proton braking line. In our opinion, these growth layers were decorated with hydrogen in the presence of oxygen, carbon and other growth impurities and defects. Such layers were not detected with further etching at the depth more than $\sim 150 \mu \mathrm{m}$ behind the braking line of the hydrogen ions (see Fig. 2-I,d).

That is, in silicon, irradiated by $6.8 \mathrm{MeV}$ hydrogen ions and annealed at $\sim 580{ }^{\circ} \mathrm{C}$, the contrast associated with the layers of growth manifests itself in a narrow line behind the braking part and does not further appear.

For comparison, in silicon irradiated by hydrogen ions with the energy of $43 \mathrm{MeV}$ by fluence $\Phi=10^{17} \mathrm{~cm}^{-2}$ at $T \leq 100{ }^{\circ} \mathrm{C}$, and annealed at $800^{\circ} \mathrm{C}$ for $0.5 \mathrm{~h}$, the gradual removal of stresses by plastic deformation with the formation of dislocations and their aggregates along the braking line was observed in the hydrogen ion braking region (at the depths $R_{p}=9400 \mu \mathrm{m}$ from the irradiated surface). With an increase in annealing temperature to $1000^{\circ} \mathrm{C}$, the contrast of the stresses associated with the layers of growth of the initial silicon was revealed (particles of the new phase and accompanying defects are formed in the growth layers of silicon crystals); it appeared for the hydrogen ions of this energy earlier in the behind of braking area (at the annealing temperature of $50{ }^{\circ} \mathrm{C}$ lower), than in the path region. Hence, the influence of irradiation on the structural characteristics of the crystal in the ion path region and behind the braking area was appeared as an accelerated generation of the thermal defects in the silicon growth layers, which was more intensive behind of the braking area of ions and was observed there at the lower annealing temperature than in the ion path region.

The results obtained for hydrogen ions of different energies indicate that the features of the silicon structure should be determined not only by the temperature of irradiation or annealing, but also by its distribution over the sample in the process of irradiation, since it can affect on the defect structure in all areas (path, braking, behind the braking part).

Micrographs of the structure of irradiated silicon after selective etching (see Fig. 2-II), which fix changes in the structure near the braking line of hydrogen ions at the corresponding depths have shown that the proton path region remains crystalline with detected typical defects (see Fig. 2-II,e,f), and behind the braking part of the sample the structure of silicon changed (see Fig. 2-II, g,h). 


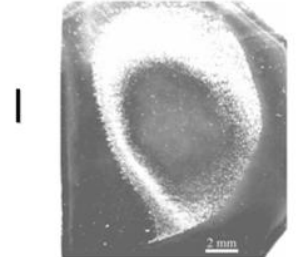

a

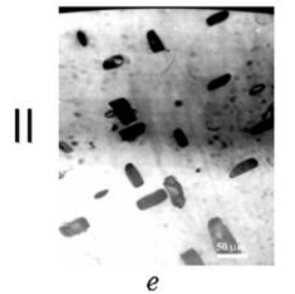

$45 \mu \mathrm{m}$

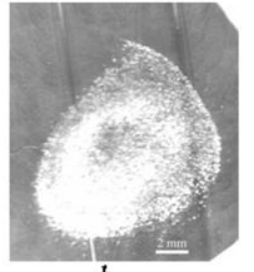

$b$

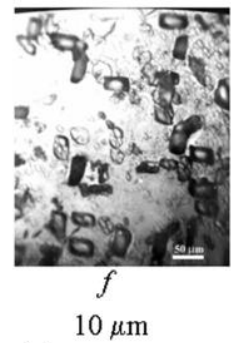

$10 \mu \mathrm{m}$

Before braking

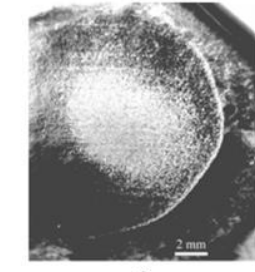

c

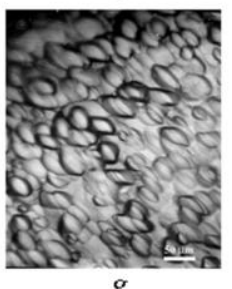

$35 \mu \mathrm{m}$

After braking
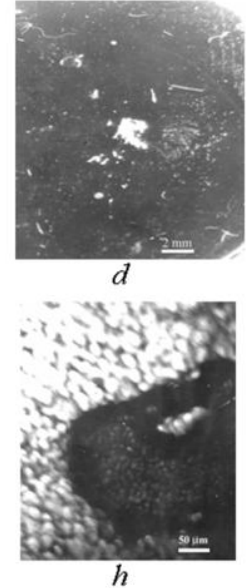

$150 \mu \mathrm{m}$

Fig. 2. I-Series of X-ray topograms of the Si structure in the irradiation plane after gradual etching at the depth of about $315 . . .510 \mu \mathrm{m}$ from the irradiation surface (near the braking line and behind it) after annealing of the irradiated silicon $\left(\Phi=10^{17} \mathrm{~cm}^{-2}\right)$ at $580^{\circ} \mathrm{C}$ for $0.5 \mathrm{~h}$.

II - Micrographs of the surface structure of irradiated Si after selective etching at the corresponding depths

\subsection{MICRODEFECT STRUCTURE OF SILICON IRRADIATED BY DEUTERIUM IONS}

After irradiation by deuterium ions, the surface of dislocation silicon turned out to be more damaged than after irradiation with hydrogen ions. According to the data of X-ray topography and selective etching, it was found that the greatest structural failures (disordering) was observed in the region of deuterium ion braking, where the concentration of defects was maximal.

Picture of the selective etching of silicon irradiated by deuterium ions with a fluence of $10^{17} \mathrm{~cm}^{-2}$ is given in Fig. 3 and it shows the modification of etched band of stresses along the braking line of ions (1) from edge to center of the irradiated region of sample (Fig. 3,a-e).

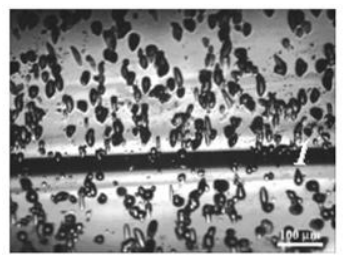

a

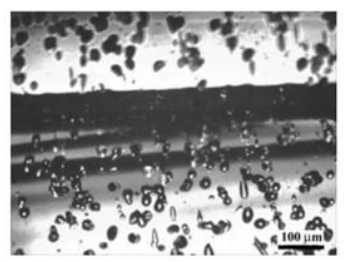

d

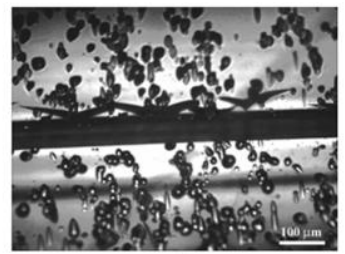

$b$

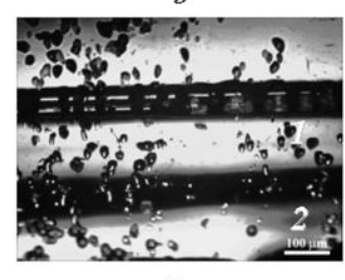

e
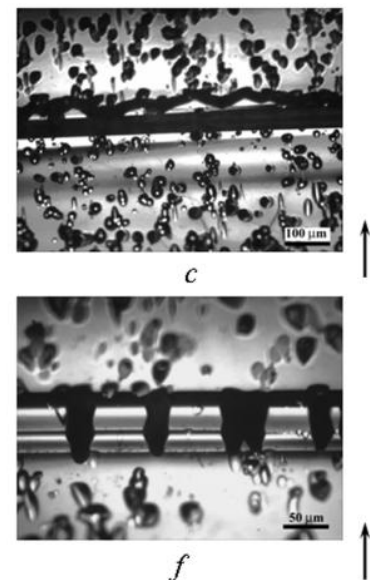

Fig. 3. Micrographs the selective etching of Si irradiated by $13.6 \mathrm{MeV}$ deuterium ions with fluence of $10^{17} \mathrm{~cm}^{-2}$; modification of braking band (1) from edge to center (a-f) of the irradiated region of sample; intersection of the braking band by the stacking faults $(e, f)$; the additional etched line $(2)$ of stresses $(e)$. The arrows indicate the direction of irradiation

In the ion path region in $\mathrm{Si}$, the additional etched band of stresses 2 appeared near the center of the irradiated area (at the distance of $130 \mu \mathrm{m}$ from the first band and closer to the surface), where the temperature of the silicon sample during irradiation was maximal (see Fig. 3,e). The width of this band was about $100 \mu \mathrm{m}$.

The braking band of ions (after selective etching) expanded and became more complicated closer to the center of the irradiated region (see Fig. 3,b-e). Near this band from the side of the unirradiated volume the stacking faults appeared (see Fig. 3,b,c), which closer to the center of the sample intersected the braking band at almost the right angle (see Fig. 3,e,f). Such process is obviously associated with the presence of dislocations in the initial silicon, their movement and interaction with radiation defects during irradiation (under conditions of high temperature and large concentrations of radiation defects).

It was established that for deuterium ion irradiation, the width of the etched braking band from the edge of irradiated region to its center varied from 30 to $130 \mu \mathrm{m}$ in the center of the sample and then again decreased to $20 \mu \mathrm{m}$. The minimal values of this parameter were obtained at the edge of the irradiation area, where the 
sample temperature was lower due to cooling. According to profilometry, the depth of the etched braking band was from 550 to $650 \mu \mathrm{m}$, and the depth of the second band was about $150 \mu \mathrm{m}$.

It was found that in the center of the sample, where the irradiation temperature was maximal, the additional etched lines of stresses appeared, due to probably by intense heating.

The etched lines of stresses did not occurred in the region of the silicon behind the braking band of deuterium ions, that is, during irradiation of dislocation silicon with deuterium ions the long-range effect (the propagation of defective structure in the region of sample behind the braking band of ions) did not observed, which may be connect with high energy release and, accordingly, with high temperature of the sample during irradiation.

Thus, it was found that irradiation with high energy deuterium ions makes it possible to form thin layers up to $200 \mu \mathrm{m}$ wide in the bulk of silicon at depths up to $R_{p}=780 \mu \mathrm{m}$, which have properties different from those of the original matrix.

Comparing the structure of the path and braking regions in silicon irradiated by the $6.8 \mathrm{MeV}$ hydrogen and $13.6 \mathrm{MeV}$ deuterium ions, one can conclude that with the increase in the ions energy, the defect formation in both regions has became complicated - the additional line of stresses appears. The braking line itself has the different width: it narrower at the edges and wider in the center of the irradiated region that probably is due to greater cooling on the edges of the crystal during the irradiation process; it is also possible due to the heterogeneity of the ion beam.

\subsection{MICRODEFECT STRUCTURE OF SILICON IRRADIATED BY HELIUM IONS}

The structure of $\mathrm{Si}$ on the surface, in the path and braking regions of the helium ions, turned out to be the most damaged (compared to hydrogen and deuterium irradiation), which could be expected since the energy and mass of helium ions are higher than those for the hydrogen and deuterium ions.

For comparison in Fig. 4 are shown threedimensional AFM images of silicon samples before and after irradiation by $6.8 \mathrm{MeV}$ hydrogen ions with fluence of $10^{16} \mathrm{~cm}^{-2}$ and by $27.2 \mathrm{MeV}$ helium ions with fluence of $10^{17} \mathrm{~cm}^{-2}$ [7]. The root-mean square surface roughness of silicon samples before irradiation was about $0.5 \mathrm{~nm}$. After irradiation with hydrogen ions, this quantity grew to $5 \mathrm{~nm}$, and after irradiation with helium ions to $20 \mathrm{~nm}$. One can see that the silicon surface irradiated with hydrogen ions became rougher in comparison with the surface of the initial material, but the surface roughness after irradiation with helium ions increased even more. This testifies to a considerable destruction of the near-surface Si layer.

In Ref. [15] X-ray topography of irradiated silicon sample, after polishing and chemical etching, displayed significant disruption of the structure in the braking region of helium ions at the depth about $360 \mu \mathrm{m}$. On the micrographs of the silicon surface obtained by scanning electron microscopy after irradiation by the fluence of $10^{17} \mathrm{~cm}^{-2}$ under the variation of the beam current density in the range of $0.25 \ldots 0.45 \mu \mathrm{A} / \mathrm{cm}^{2}$, the ordered structures of defects in the form of stress lines, perpendicular to the direction of the ion beam current, were visible both in the region of the ion path and behind the braking line.

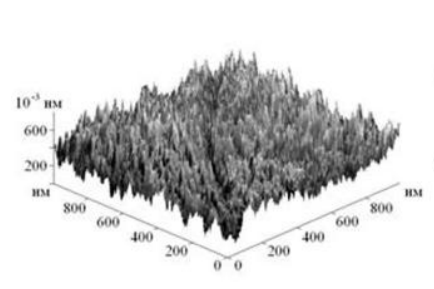

$a$

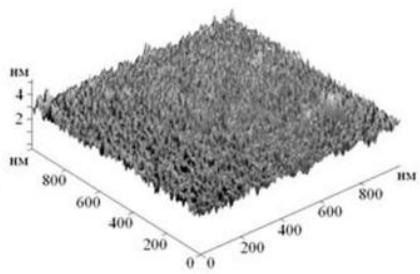

$b$

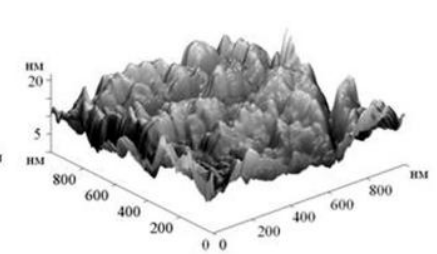

$c$

Fig. 4. AFM image of the Si surface before (a) and after irradiation by hydrogen ions with fluence $10^{16} \mathrm{~cm}^{-2}(\mathrm{~b})$, and by helium ions with fluence $10^{17} \mathrm{~cm}^{-2}(\mathrm{c})$

When the beam current density increases up to $1 \mu \mathrm{A} / \mathrm{cm}^{2}$, lines of the stresses appeared only in the path region of ions. The long-range effect was not observed in these conditions. The number of stress lines in the path region of the sample was determined likely by the temperature distribution over the irradiated surface, declining from the centre (b) to the edge (a) of the sample, where the maximal cooling took place (Fig. 5). Fig. 5 shows micrographs of dislocation-free silicon, irradiated by $27.2 \mathrm{MeV}$ helium ions $\left(\Phi=10^{17} \mathrm{~cm}^{-2}\right)$ after selective etching. It is seen that the etched braking line 1 is not the same in width: on the edge of the irradiated region the braking line is narrower (a) than in the center (b). In the vicinity of it the individual dislocations, dislocation loops and cavities were observed (c). The width of the braking line 1 is maximal in the center of the irradiated area (nearly $90 \mu \mathrm{m}$ ).

The results of metallographic study are shown in Fig. 6 for the $\mathrm{Si}$ sample irradiated by fluence of $10^{17} \mathrm{~cm}^{-2}$ at the ion beam current density close to $1 \mu \mathrm{A} / \mathrm{cm}^{2}$ after the selective etching. It turned out in a significant increase that the braking region of helium ions was a strongly damaged region of silicon consisting of voids with various sizes and shapes, etched as a continuous layer (see Fig. 6,a,b), and in the form of individual clusters, accompanied by the formed dislocation loops (see Fig. 6,c). The number of layers depends on the intensity of the ion beam and, hence, the heating temperature of the sample during irradiation. 


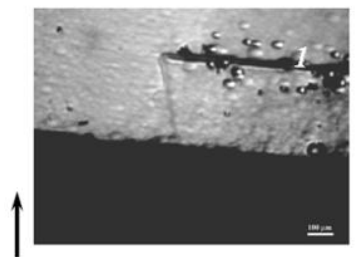

$a$

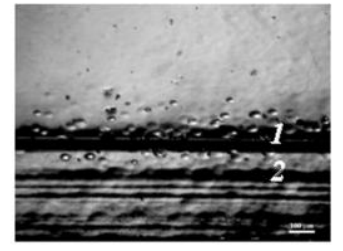

$b$

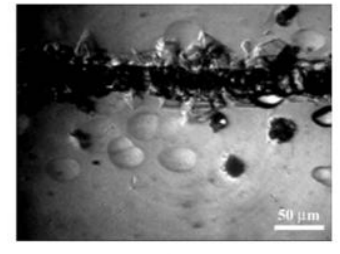

Fig. 5. Micrographs of the selective etching of Si irradiated by $27.2 \mathrm{MeV}$ helium ions with fluence of $10^{17} \mathrm{~cm}^{-2}$ at

the beam current density $1 \mu \mathrm{A} / \mathrm{cm}^{2}: a$-at the edge; $b$-in the center of the irradiated region of the sample;

$c$-dislocations, dislocation loops and cavities near the braking region; line 1 corresponds to the braking region;

line 2 is the additional line of stresses. The direction of irradiation is indicated by an arrow

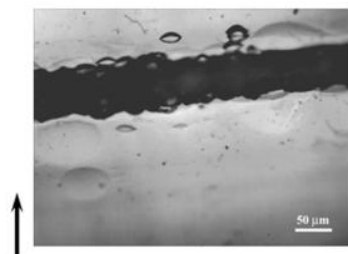

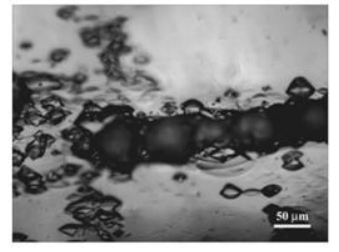

$b$

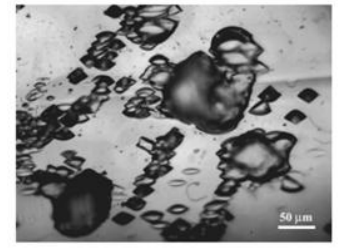

$c$

Fig. 6. Micrographs of the selective etching of Si irradiated by $27.2 \mathrm{MeV}$ helium ions with fluence of $10^{17} \mathrm{~cm}^{-2}$ : $a, b$-the braking region is etched as a continuous layer; $c$-the braking region possesses the cavities and dislocations that accompany them. The direction of irradiation is indicated by an arrow

Microprofilogram of the sample surface shows the swelling of silicon in the region of the helium ions' path [15]. The difference in the profile of the irradiated and unirradiated parts of the sample is about $8 \mu \mathrm{m}$. Images of the surfaces of the initial and irradiated $\mathrm{Si}$ samples $\left(10^{17} \mathrm{~cm}^{-2}\right)$ obtained using the atomic force microscope (see Fig. 4) confirm the swelling of Si in the path region of ions: roughness of the irradiated surface (c) greatly increased in comparison with the unirradiated one (a).

The micrographs of the helium ions' path and the braking parts of silicon received by the scanning electron microscope showed that its structure was not monocrystalline but fragmentary (Fig. 7,a) and possessed the ordered lines (n) parallel to the braking line (m) of helium ions (see Fig. 7,b).

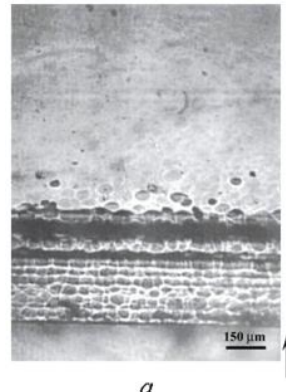

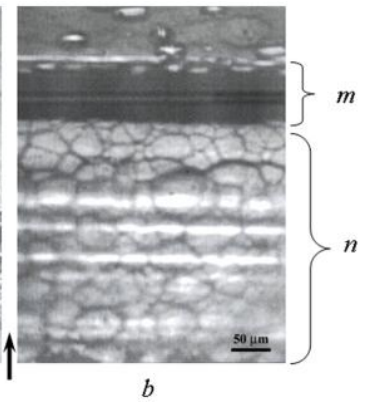

At the annealing of silicon, a gradual transition of the structure of such layer from amorphous to polycrystalline state is observed, which is accompanied by the formation of a large concentration of extended defects. In the process of recrystallization the segregation of gas $(\mathrm{H}, \mathrm{Ne}, \mathrm{Ar})$ (depending on its diffusion in $\mathrm{Si}$ ) occurs, its narrowly linear distribution, accumulation and agglomeration into the bubbles. With heating the gas leaves the bubbles and forms the voids. The processes are accelerated with the growth of ion energy; and the size of defects, their complexes and defect areas increase also. In the ion path region of $\mathrm{Si}$, lines of stresses appear the number and size of which are determined by the mass and energy of the ions.

The development of the cascade of atomic collisions in the material when irradiated with high-energy ions occurs in very short time intervals $\left(\sim 10^{-12} \mathrm{~s}\right)$, and the limiting pressure in the cascade region is several tens of kilobars. The sharp expansion of the heated cascade region, where the temperature reaches $\sim 5000 \ldots 6000 \mathrm{~K}$, generates a number of processes, such as amorphization of the material, subsequent recrystallization and the possible occurrence of a polycrystalline region with stacking faults and dislocations [16]. Collective interaction processes in conditions of high density of atomic collisions can stimulate inner phase transformations, causing the formation of layers of defects and changing the parameters of the matrix.

The formation of voids during the implantation of high-energy gas ions is most likely due to the high concentration of defects of the vacancy type. The vacancies, merging into the complexes, can remove stresses in the lattice, including those associated with the precipitation of growth impurities (oxygen or carbon), and prevent the formation of dislocations.

When silicon was irradiated with both hydrogen ions and helium ions, the effect of defect propagation in the form of stress lines behind the limits of the braking region was observed. This effect depended on the ion
At present, it is known that the implantation of light ions of kiloelectronvolt energies in silicon at room temperature and fluences $\geq 10^{16} \mathrm{~cm}^{-2}$ leads to the formation of an amorphous layer in the ion braking region [4]. The thickness of this layer will grow with increasing of fluence. 
beam current density (irradiation intensity) and occurred only when the beam current density was less than $0.45 \mu \mathrm{A} / \mathrm{cm}^{2}$ (i.e. at lower irradiation temperatures).

The orderliness of the defective system might indicate on the wave mechanism of its formation. Although the well-known autowave mechanism [8] cannot explain the long-range and ultra-long-range propagation of the action of irradiation in part of the crystal behind the region of ion braking, since it provides for maintaining the amplitude of the propagation of the concentration front of radiation defects due to plastic deformation. However, as shown by our data [12], plastic deformation in samples irradiated by protons occurs at a higher temperature (the rupture of $\mathrm{Si}-\mathrm{H}$ bonds occurs at a temperature of about $600{ }^{\circ} \mathrm{C}$ ) than the sample temperature during irradiation.

At the same time, another mechanism of radiation influence propagation was examined in work [9], namely, by engaging soliton-like pulses. In the case of high irradiation fluences and high ion energies, as it was in our work, a huge number of soliton-like pulses can be generated at the particle collision with the surface. It is probable that a new powerful sequence of pulses would be generated in the ion braking region as well $[17,18]$. Owing to a high speed of pulse propagation in the crystal, the energy transfer and the energy redistribution over the crystal volume could be realized quickly enough, which would govern the long-range effect.

In our opinion, the soliton-like mechanism of radiation effect propagation is the most probable one under our irradiation conditions. It does not contradict any other known wave mechanisms, because solitons are "particlelike" nonlinear waves. In work [19], by analyzing the models of self-organization in various systems, attempts were made to formulate the general conditions needed for periodic coherent processes to be invoked. Under our conditions, the soliton mechanism of periodic process generation may probably be implemented.

Hence, the formation of a periodic defect structure can find its explanation in the framework of the synergetic approach, as a result of the defect selforganization in the irradiated crystal [20].

Summing up, it should be noted that understanding the processes of orderly accumulation and distribution of defects and impurities during ion irradiation is necessary to control their number and localization.

\section{CONCLUSIONS}

1. The complex studies of the effect of irradiation by high-energy light ions on silicon crystals have shown that with a large energy release in a thin layer of a crystal during irradiation, the favorable conditions can be created for the controlled introduction of structural defects, and also for occurrence of effects of ordering and long-range. The identified effects can be applied in the construction of a modern theory of the interaction of radiation with matter.

2. It was found that during high-energy irradiation of silicon with hydrogen and helium ions in the case of large fluences $\left(\geq 10^{16} \mathrm{~cm}^{-2}\right)$, the formation of defects passes through the ordering stage (in the form of stress lines, perpendicular to the direction of the propagation of ion beam).

3. It was shown that when irradiating silicon with helium ions, the ordered defect structure extends both on the ion path and behind of the braking region. The number and location of the stress lines relative to the braking line depends on the magnitude of the ion beam current density. It was revealed that in the region of the ion path, the linear defect structure is fragmented, and the braking line of ions consists of voids.

4. The propagation of the defects in silicon in the form of ordered linear structures (in the case of irradiation both with hydrogen ions and helium ions) behind the ion braking region indicates the presence of the long-range effect, which was observed at the ion beam current density of $\leq 0.45 \mu \mathrm{A} / \mathrm{cm}^{2}$. It is assumed that the formation of the ordered defect structure can be the result of the process of self-organization of radiation defects, and the long-range effect can be explained by the realization of a soliton mechanism.

5. It was established that the utilization of light ions of megaelectronvolt energies cause the formation in the volume of silicon at depths up to several hundred microns of the ordered layers, related with defects, of the different nature and width, which makes it possible to change the properties of silicon. The nature of defect formation (the number and width of formed lines of stresses) in the conditions of silicon irradiation by large ion fluences depends on the ion mass and energy, irradiation temperature and properties of the crystal itself.

6. It was revealed that the degree of damage of irradiated $\mathrm{Si}$, both in the ion path region and in the braking area, increases and complicates with increasing energy and mass of ions. More orderly and narrower lines of stress associated with defects were observed in silicon irradiated by hydrogen ions. In this case the surface of silicon investigated by the atomic-force microscope was the least damaged.

7. It was established that irradiation by deuterium ions with the megaelectronvolt energies makes it possible to form thin layers $(30 \ldots 200 \mu \mathrm{m})$ in the bulk of silicon at depths up to $780 \mu \mathrm{m}$, which have properties different from those of the original matrix. The ability to change the properties of silicon layer by layer is important to ensure the current needs of micro- and nanoelectronics.

8. It was found that the presence of dislocations in $\mathrm{Si}$ in the process of deuterium ion irradiation leads to their movement and their intersection of the braking line due to the formation of stacking faults. The final picture of the formation and ordering of defects is determined by the interaction of growth and radiation defects and the temperature during irradiation.

9. It was revealed that the use of ions of gases of megaelectronvolt energies $(\mathrm{H}, \mathrm{D}, \mathrm{He})$ promotes, on the one hand, to create in the ion braking region of silicon a broken layer of a larger size than in the case of kiloelectronvolt ions, and on the other hand, it can contribute to the accelerated recrystallization of amorphous layers due to the temperature increase during irradiation as a result of an increase in the energy of ions. This contributes to the layerwise segregation of 
impurities and defects in $\mathrm{Si}$, that is, the change in properties both in the ion path of the silicon and behind it. To obtain the specific values of these changes, it is important to control the regime of irradiation (type of ions, their energy, fluence and temperature of irradiation). With regard to the material being irradiated, it is necessary to have information concerning the structure, the presence of doping and growth (background) impurities (such as oxygen, carbon), other defects and their distribution in the bulk of the crystal.

\section{Acknowledgement}

The authors are sincerely grateful to Sugakov V.I., Corresponding Member of the NAS of Ukraine, for his interest in the work and useful discussion of the results.

\section{REFERENCES}

1. D.F. Moore, J.H. Daniel, J.F. Walker. Nano- and microtechnology applications of focused ion beam processing // Microelectronics Journal. 1997, v. 28, N 4, p. 465-473.

2. J.W. Rabalais, A.H. Al-Bayati, K.J. Boyd, D. Marton, J. Kulik, Z. Zhang, W.K. Chu. Ion-energy effects in silicon ion-beam epitaxy // Phys. Rev. B. 1996, v. 53, N 16, p. 10781-10792.

3. V.M. Vishnyakov, S.E. Donnelly, G. Carter. The influence of impurities on the growth of helium-induced cavities in silicon // J. Appl. Phys. 2003, v. 94, N 1, p. 238-244.

4. E. Oliviero, S. Peripolli, L. Amaral, P.F.P. Fichtner, M.F. Beaufort, J.F. Barbot, S.E. Donnelly. Damage accumulation in neon implanted silicon // J. Appl. Phys. 2006, v. 100, N 4, p. 043505 (10).

5. K.J. Abrams, J.A. Hinks, C.J. Pawley, G. Greaves, J.A. van den Berg, D. Eyidi, M.B. Ward, S.E. Donnelly. Helium irradiation effects in polycrystalline Si, silica, and single crystal Si // J. Appl. Phys. 2012, v. 111, N 8, p. 083527 (6).

6. R. Kögler, A. Peeva, P. Werner, W. Skorupa, U. Gösele. Gettering centres in high-energy ionimplanted silicon investigated by point defect recombination // Nucl. Instrum. Methods Phys. Res. B. 2001, v. 175-177, p. 340-344.

7. N.L. Dmitruk, O.S. Kondratenko, M.B. Pinkovska, V.I. Khivrich, L.A. Vlasukova, P.V. Kuchynsky. Optical and sensitive properties of nanostructured silicon irradiated with high-energy particles (protons, $\alpha-$ particles, and heavy ions) // Ukr. J. Phys. 2010, v. 55, N 7, p. 808-816.

8. A.S. Alalykin, P.N. Krylov, M.V. Shinkevich. The long-range effect in semiconductors // Vestnik Udmurtskogo universiteta. Ceriya fizika i himiya. 2005, N 4, p. 141-152 (in Russian).
9. S.G. Psahe, K.P. Zolnikov, R.I. Kadyirov, G.E. Rudenskiy, Yu.P. Sharkeev, V.M. Kuznetsov. On the possibility of the formation of soliton-like pulses under ion implantation // Technical Physics Letters. 1999, v. 25, N 6, p. 7-12.

10. N.P. Aparina, M.I. Guseva, B.N. Kolbasov, S.N. Korshunov, A.N. Mansurova, Yu.V. Martynenko, I.V. Borovitskaja, L.I. Ivanov. Some aspects of the long range effect // Problems of Atomic Science and Technology. Series “Thermonuclear Fusion”. 2007, N 3, p. 18-27.

11. N.N. Gerasimenko, A.N. Mikhailov, V.V. Kozlovsky, O.A. Zaporozhan, N.A. Medetov, D.I. Smirnov, D.A. Pavlov, A.I. Bobrov. Structure and luminescence of silicon irradiated by protons // Journal Perspektivnye Materialy. 2013, N 8, p. 18-23 (in Russian).

12. A.A. Groza, P.G. Litovchenko, M.I. Starchyk. Radiation Effects in Infrared Absorption and Silicon Structure. Kyiv: "Naukova dumka", 2006, 124 p.

13. V.I. Varnina, A.A. Groza, P.G. Litovchenko, M.B. Pinkovs'ka, L.A. Polivtsev, M.I. Starchik, V.I. Khivrych, G.G. Shmatko. Optical and structural studies of proton-irradiated silicon monocrystals // Ukr. J. Phys. 2003, v. 48, N 3, p. 269-274.

14. A.A. Groza, P.G. Litovchenko, M.I. Starchik, V.I. Khivrich, G.G. Shmatko. Long-range effects in silicon single crystals irradiated with protons and alphaparticles // Ukr. J. Phys. 2010, v. 55, N 6, p. 699-705.

15. M.I. Starchyk, L.S. Marchenko, M.B. Pinkovska, G.G. Shmatko, V.I. Varnina. Voids' layer structures in silicon irradiated with high doses of highenergy helium ions // Semiconductor Physics, Quantum Electronics \& Optoelectronics. 2015, v. 18, N 3, p. 292296.

16. J. Nord, K. Nordlund, J. Keinonen. Amorphization mechanism and defect structures in ionbeam-amorphized Si, Ge, and GaAs // Phys. Rev. B. 2002, v. 65, N 16, p. 165329 (14).

17. V.V. Ovchinnikov. Radiation-dynamics effects. Potential for producing condensed media with unique properties and structural states // Phys. Usp. 2008, v. 51, N 9, p. 955-964.

18. V.V. Ovchinnikov. Dynamic long-range effects under irradiation. Radiation methods for processing materials // 8-th Intern. Conf. "Interaction of Radiation with Solids”, Minsk, Belarus, 2009, p. 113-116.

19. O.V. Chalyi, V.P. Lukomskyi, I.S. Hanzha, Ya.V. Tsekhmister, K.O. Chalyi. Nonlinear Processes in Physics: Oscillations, Waves, Self-Organization. Kyiv: "Chetverta khvylia", 2005, 359 p.

20. V.I. Sugakov. Fundamentals of Synergetics. Kyiv: "Oberehy", 2001, 287 p.

Article received 21.02.2019

\section{РАДИАЦИОННО-ИНДУЦИРОВАННЫЕ ЭФФЕКТЫ В КРЕМНИИ}

\section{Г.П. Гайдар, М.Б. Пинковская, М.И. Старчик}

Представлены результаты комплексных исследований структурных свойств кремния, облученного легкими ионами мегаэлектронвольтных энергий флюенсами, превышающими $10^{16} \mathrm{~cm}^{-2}$. Выявлено, что при облучении в условиях большого энерговыделения в тонком слое кристалла могут создаваться 
благоприятные условия для контролируемого введения структурных дефектов и возникновения эффектов упорядочения и дальнодействия. Установлена возможность послойной модификации свойств кремния на глубинах до 780 мкм при облучении ионами, что может быть использовано для удовлетворения актуальных потребностей микро- и наноэлектроники.

\section{РАДІАЦІЙНО-ІНДУКОВАНІ ЕФЕКТИ В КРЕМНІї}

\section{Г.П. Гайдар, М.Б. Пінковська, М.І. Старчик}

Представлено результати комплексних досліджень структурних властивостей кремнію, опроміненого легкими іонами мегаелектронвольтних енергій флюенсами, що перевищують $10^{16}$ см $^{-2}$. Виявлено, що в разі опромінення в умовах великого енерговиділення в тонкому шарі кристала можуть створюватися сприятливі умови для контрольованого введення структурних дефектів і виникнення ефектів упорядкування і далекодії. Встановлено можливість пошарової модифікації властивостей кремнію на глибинах до 780 мкм у разі опромінення іонами, що може бути використано для забезпечення актуальних потреб мікро- i наноелектроніки. 